\title{
THE DIAGNOSIS AND TREATMENT OF SIMMONDS' DISEASE
}

\author{
By V. K. Summers, M.D., M.R.C.P. \\ Visiting Physician Walton Hospital, Liverpool ; Hon. Physician Providence Hospital ; Ássistant Hon. Physician
} Liverpool Chest Hospital

\section{Definition}

Simmonds' disease is caused by destruction of the anterior lobe of the pituitary gland, from any cause. No other definition is necessary or adequate. Much confusion exists about this disease because of the assumption made in many of the reviews that cachexia and progeria are cardinal signs. Escamilla and Lisser, Silver, Calder, state in their reviews that emaciation is one of the principal signs of destruction of the anterior pituitary. It is safe to say that the diagnosis of Simmonds' disease is missed in the majority of cases because of reliance on this sign.

\section{Aetiology}

The most common cause of Simmonds' disease is post-partum necrosis of the anterior lobe of the pituitary. The original case described by Simmonds' was of this type. Sheehan has stressed the importance of collapse at the time of the significant delivery, in the production of post-partum necrosis of the anterior pituitary. A history of a delivery complicated by severe ante-partum or postpartum haemorrhage can usually be obtained in cases of post-partum Simmonds' disease. Many examples of this syndrome have been described in the literature by Balen, Berblinger, Biggart, Heinrichs, Merz, Simmonds, Sheehan, etc. Destruction of the anterior lobe of the pituitary can be accomplished in other ways ; trauma, especially bullet wounds and fractures of the base of the skull, may cause destruction of the parenchyma of the anterior pituitary. Acceptable cases of this disease due to trauma have been described by Reverchon, Lerman and Means, etc. Tuberculosis and syphilis may destroy completely the pituitary gland and cases due to these causes have been described by Williams, Esser, Knoll, etc. Tumours of the pituitary and the supra-sellar cysts may, by compression, destroy the gland cells of the anterior lobe. Numerous examples of hypopituitarism due to the effects of tumours have been described by Aitken and Russell, Globus, Hoet, Cushing, etc.

Since the most important cause of Simmonds' disease is post-partum necrosis of the anterior pituitary, it follows that the age incidence of this disease is greatest between 2045 years, and that the disease is much commoner in women than men. The following description is that of a typical post-partum case.

A history is nearly always obtainable of a delivery complicated by severe haemorrhage. The earliest signs of the disease are manifested during the first few days of the puerperium. Failure of lactation or indeed of engorgement of the breasts is noticed. Convalescence from the delivery is often slow and it is a long time before these patients feel well enough to look after their homes. The march of symptoms is fairly constant and can be readily visualized by realizing that they depend on failure of the pituitary hormones.

\section{General Appearance}

The classical concept of the appearance of a patient suffering from Simmonds' disease, is of an emaciated, prematurely senile woman, but the true appearance is vastly different. These patients are of average nutrition and have a pale, dry, rather sallow skin. Their appearance suggests a degree of anaemia much more severe than is found when haematological examinations are carried out. Progeria is unusual. The head hair is normal in amount and little altered in texture. The eyebrows tend to be thin. The appearance of these patients suggests a diagnosis of anaemia, with the possibility of a subthyroid condition. 


\section{Gonadotrophic Hormone}

Disturbance of menstruation, ranging from amenorrhoea to irregular or scanty periods, is a constant sign. Menstruation may never occur again after the significant delivery. At the same time loss of libido, and atrophy of the genitalia, occur. The uterus becomes small and hypoplastic; vaginal examination reveals a small button of tissue at the top of the vagina - the atrophic cervix.

The body of the uterus may not be palpable. Glycogen disappears from the vagina and Doderlein's bacilli are not found. The external genitalia assume a senile appearance. Loss of pubic hair and axillary hair is a constant finding within 2-3 years of the onset of the disease.

\section{Thyrotrophic Hormone}

The appearance of many patients suffering from Simmonds' disease bears a striking resemblance to myxoedema; so marked is this resemblance that the term pituitary myxoedema has been coined by American authors (Lerman, Means). The skin of the face and arms is dry and scaly, and frequently has a faint yellow colouration. The thyroid gland is usually impalpable, and at postmortem is found to be an atrophied remnant. Sensitivity to cold is pronounced; these patients sit huddled near the fire even in comparatively warm weather. All display a wellmarked erythema $a b$ igne on their legs. The B.M.R. is usually low, average readings being 28 per cent.

\section{Adrenotrophic Hormone}

Lack of the pituitary adrenotrophic hormone produces changes which are not readily discernible clinically but which nevertheless afford important confirmatory evidence in the diagnosis of Simmonds' disease. It is probable that the adrenal lesions in Simmonds' disease are responsible for the loss of pubic and axillary hair. The excretion of 17 -ketosteroids in the urine is reduced to zero and affords a most important confirmatory sign. The Kepler test of adrenal function, involving delayed excretion of chloride with relative retention of urea, gives readings similar to those found in Addison's disease. Addisonian pigmentation of the skin and mucous membranes is never found.

\section{Blood Changes}

A moderate degree of hypochromic anaemià is frequently found, but is never as much as is expected from the appearance of the patient. Blood sodium levels are frequently within normal limits, but the blood cholesterol is often raised. Blood sugar levels tend to be low and spontaneous hypoglycaemia, which may be fatal, is of common occurrence. Extreme insulin sensitivity and hypoglyaemic unresponsiveness are usual findings and form the bases for the insulin tolerance test devised by Fraser and Smith. So sensitive to insulin are patients suffering from Simmonds' disease that it is wiser when the diagnosis is suspected, to use smaller quantities of insulin than Fraser and Smith recommend; .05 units of insulin $/ \mathrm{Kg}$. is an adequate dose for the test.

The blood pressure is usually normal and the very low levels found in Addison's disease do not appear. Electrocardiographic changes are not constant. Occasionally low voltage in all leads, with flattening or inversion of the $\mathrm{T}$ waves is found; a finding reminiscent of the E.C.G. in myxoedema. Patients suffering from Simmonds' disease show a profound depression of insulin and creatinine clearance. Normal values are often found for the N.P.N. and blood urea.

\section{Diagnosis}

Anorexia nervosa is frequently confused with Simmonds' disease, because emaciation is regarded as one of the principal signs of anterior hypopituitarism. The main points of differentiation may be tabulated :-

Anorexia Nervosa

Frequent in nulliparous women.

Psychological factors important.

Emaciation often severe.

Pubic and axillary hair present.

Normal genitalia although Extreme atrophy of amenorrhẹa frequent.

Ketosteroid excretion normal (low in late stages).

No evidence of adrenal dysfunction.

Anorexia characteristic. Appetite usually normal. 
Myxoedema is less frequently confused with Simmonds' disease, but several of the cases which I have recently seen have been diagnosed as myxoedema. Two important differential tests are the ketosteroid excretion which in myxoedema yields figures of $\mathrm{I} .5$ to $\mathrm{I0.3}$ $\mathrm{mgm}$./day and the insulin tolerance test.

Simmonds' disease due to causes other than post-partum necrosis is much less common, but may be found in men. An incomplete syndrome usually results with hypogonadism as the predominating feature.

\section{Treatment}

Reports of treatment in cases of Simmonds' disease are mainly unreliable, because of the confusion existing between this disease and anorexia nervosa. Oestrin, prolans corticotrophic hormone, thyroxine, insulin, liquid extract of pituitary have all been given successfully in cases of anorexia nervosa which have been wrongly diagnosed as Simmonds' disease. Kylin and Vogt have reported cures in Simmonds' disease by the transplantation of pituitary glands from calves and new-born infants; unfortunately their cases are undoubtedly anorexia nervosa.

The ideal treatment of Simmonds' disease would be replacement of the anterior pituitary hormones by synthetic or natural products. As yet this is not practicable. Recently fairly pure adreno-corticotrophic hormone and thyrotrophic hormone preparations have been made available (Cortrophin and Ambinon, Organon, Ltd.). Administration of these substances to patients, undoubtedly produces improvement. Muscular strength and energy are increased and cold sensitivity becomes less marked.

Similar improvement has been claimed by the administration of sodium chloride and gonadogen (pregnant mare's serum) by Lerman and Stebbins. They recommend 20 units of gonadogen three times a week for two weeks, followed by an interval of two weeks and a repetition of the course.

Beneficial effects from male hormone therapy have been reported by Werner and West (1943) and Lisser and Curtis (1945). Methyl testosterone was given orally in doses of $100 \mathrm{mgm}$. daily. Regrowth of body hair, with increased physical and sex vigour were claimed. Williams et alia (1945) also reported on the use of testosterone in Simmonds' disease and confirmed the increase in physical strength noticed following this form of therapy.

The use of thyroid extract is dangerous and may precipitate an adrenal crisis.

Sheehan and Murdoch (1938) reported a case of Simmonds' disease in which a further pregnancy ensued. Spontaneous improvement is rare, but improvement is quite obvious within the first few months of pregnancy, and if the subsequent delivery is normal this improvement is maintained. Pregnancy is, however, only likely to occur in those patients who have had a small necrosis of the anterior pituitary and who manifest mild signs of Simmonds' disease.

The therapy of Simmonds' disease is at present unsatisfactory, but the production of pituitary trophic factors in relatively pure form offers hope for the future.

\section{BIBLIOGRAPHY}

AITKEN, R. S., RUSSELL, D. (1934), Lancet, 2, 802.

BALEN, G. F. (1939), Acta. Med. Scand., ror, 433.

BERBLINGER (1928), Cent.f. Allg. Path., 44, 161.

BIGGART, J. H. (1941), Ulster Med. F., ro, 87.

CALDER, R. M. (1932), Bull. Fohns Hopk. Hosp., 50, 87.

CUSHING, H. (rgiz), "The Pituitary Body and its Disorders," Phil.

ESCAMILla, R., LISSER, H. (1,938), Calif. and West. Med. F., $53,210$.

ESSER, A. (1927), Cent. f. Path., 39, 97.

FRASER-SMITH, J. (194I), Q.F.M., X, 297.

GLOBUS, H.; GANG, K. M. (1945), 12, 220.

HEINRICHS, H. (1932), Cent. f. Path., 56, 52.

HEMPHILL, R. E., REISS, M. (1944), B.M.尹., 2, 21 I.

HOET, M. Bull, (1933), Acad. roy. med. Belg., 13; 445.

KNOLL, W. (1922), Wien. Arch.f. Klin. Med., 4, 555.

KYLIN, E. (1937), Med. Klin., 33, 1497.

LERMAN, J., MEANS.
LERMAN, J. STEBBINS, H. D., (1942), Ұ.A.M.A., 119, 39 r.

LISSER, H., CURTIS, L. E. (1945), $\mathscr{7}$. Clin. Endo., 5, 363.

MERZ, W., FRANK (1930), Zeit f. Path., 40, 452.

REVERCHON, L., WORMS, G., ROUQUIER, A. (1921), Presse. Med., 29, 741.

ROBINSON, F. J., POWER, M. H., KEPLER, E. J. (1941), Proc. Staff. Meet. Mayo Clinic, 16, 577.

SHEEHAN, H. L. (1937), F. Path. Bact., 45, 189.

SHEEHAN, H. L. (1938), Ұ. Obst. Gyn., 45, 456.

SHEEHAN, H. L., MURDOCH, R. (1938), Lancet, , , 132.

SHEEHAN, H. L. (1939), Q.F.M., 32, 277.

SILVER, S. (1933), Arch, Int. Med., 51, 175.

SIMMONDS, M. (1914), Deut. Med. Wochn., xL, 322.

WERNER, S. C., WEST, R. (I943), F. Clin. Invest., 22, 335.

WILLIAMS, J. E. (1940), New York State. M. F., 35, 672.

WILLIAMS, R. H., WHITTENBERGER, J., BISSELL, G., WEINGLASS, Ä. R. (1945), Ұ. Clin Endo., 5, 163.

VOGT, E. (1935), Med. Klin., 31, 1393. 